\title{
Laparoscopic Management of Common Bile Duct Stones
}

\author{
Mohammed Shaaban Khalifa, MD; Mohamed Ibrahim Hassan, MD.
}

\author{
Department of General Surgery, Faculty of Medicine - Ain Shams University, \\ Cairo, Egypt.
}

Introduction: Common bile duct(CBD) stones are found in approximately $16 \%$ of the patients undergoing laparoscopic cholecystectomy $(L C)$. Till recently, the gold standard for treating CBD stones wasendoscopic removal, if that failed, then open surgery. However, in the laparoscopic era, the besttreatment for CBD stones is a matter of debate and it continues to evolve.

The objective of the presentstudy was to determine whether laparoscopic CBD exploration ( $L C B D E)$ is a safe, feasible and single-stageoption for the management of CBD stones.

Patients and methods: All patients were done in our surgery department. Out of the 450 laparoscopiccholecystectomies between 2012-2015, we did selective intraoperative cholangiogram in 45 patients(10\%) who were suspected to have CBD stones based on deranged liver function tests, dilated $C B D$ with orwithout $C B D$ stone on sonography or having the history of recent jaundice/ pancreatitis. If CBD stonewas found, either a transcystic or transcholedochal exploration was done depending on the size, site,number of stones and CBD diameter. Choledochotomy was closed over a t-tube in few numberof patients. Primary closure of $C B D$ was done in the majorityof patients and in one patient we placed an antegradestent and in another one we placed endoscopic stent into the CBD laparoscpically which was removed afterfour weeks.

Results: Till date we have performed LCBDE in 34 patients. Transcystic exploration wasdone in 10 patients and transcholedochal exploration was done in 20 cases out of which 2 patientshad minor biliary leak which settled on conservative treatment in 2-3 days. Four patients requiredconversion to open surgery as there were multiple stones. We did not have any major complication andon 6 months follow-up in 83.3\% patients, none was found to have residual stones.

Conclusion: Treatment of CBD stones depends on the resources available, technical limitations and the surgeon'sexpertise. Laparoscopic CBD exploration is a safe, feasible and single-stage option for the managementof CBD stones.

Key words: Laparoscopic surgery, common bile duct (CBD) exploration, selective intraoperative cholangiogram (IOC), choledocholithiasis.

\section{Introduction:}

Common bile duct (CBD) stones are found approximatelyin $10-16 \%$ of the patients undergoing laparoscopic cholecystectomy (LC).1-4 Until recently, it was generally agreed that if stones are detected in CBD preoperatively, it seemed appropriate to remove them prior to LC by ERCP. If CBD stonecould not be extracted by RECP, then CBD stone was extracted by open
CBD exploration. However, in the present laparoscopic era, the best treatment for patients with choledocholithiasis is a matter of debate and the management of choledocholithiasis continues to evolve. ${ }^{5}$ If the stones are found by intraoperative cholangiography during LC, the surgeon may either do the LC and refer the patient to ERCP postoperatively, or he may convert to open CBD exploration, or in the current times, he may do LCBDE. 
The advent of ERCP and ES dramatically changed the management of CBD stones. ERCP is a quick and often painless procedure, successful in $>90 \%$ of the patients. ${ }^{6}$ However, there are few adverse effects of the procedure like pancreatitis, bleeding, failure to clear duct, cholangitis, recurrent stone formation. ${ }^{7}$ The second revolution in the management of the bile duct stones came with advancement in the laparoscopic surgery. The objective of the present study is to determine that laparoscopic CBD exploration is a safe, feasible and single-stage option for the management of CBD stones.

\section{Patients and methods:}

A retrospective analysis was done on the patients undergoing LC between January 2012 and April 2015. Thorough history and clinical examination was done and the patient was investigated in the form of routine blood tests, liver function tests including, amylase and abdominal sonography. If there was suspicion of CBD stone,on the basis of predictors of CBD stones as shown in Table (1), patients were subjected to selective Intraoperative cholangiogram(IOC). We have not used any scoring system for predicting the CBD stone. Patients with choledocholithiasis associated with mild gall stone pancreatitis were operated during the same admission if the Ranson's score was 3 or less. If the Ranson's score was $>3$, surgery was postponed till the acute bout of pancreatitis subsided.

Patients who were unfit for operation or those with severe pancreatitis/ cholangitis, and those who were diagnosed to have CBD stone with bile duct diameter $<6 \mathrm{~mm}$ were subjected to ERCP and were excluded from the present study. Also patients who had previous upper abdominal surgery were excluded from the present study. Patients who had previous ERCP with failure of stone extraction were subjected to LCBDE.

Technique: All operations were done supervised by senior consultants and we kept improving our learning curve to shorten the operation time, decrease complications rate, and transfer the experience to junior staff in our 8B unit.
The standard 4-port configuration for LC was used. A fifth port was made inbetween the right midclavicular and epigastric port just below the subcostal margin for inserting the choledochoscope, $2 \mathrm{~mm}$ for transcystic exploration and $5 \mathrm{~mm}$ for transcholedochal exploration.

The fundus of the gall bladder was retracted towards the right shoulder and the Hartman's pouch was retracted downwards and outwards toward the right hip. Dissection began at the neck of the gall bladder and continued proximally until the junction of gall bladder with the cystic duct was clearly defined. Dissection was continued proximally on to the cystic duct until there was adequate length to perform cholangiogram. Then the cystic duct was milked to wardsthe gall bladder to dislodge any cystic duct stone into the gall bladder. A clip was applied on the gall bladder side to prevent any back slippage of gallstone into the CBD and to prevent biliary spillage into the operative field.

IOC was done using a ureteric catheter (4-5 Fr) or an infant feeding tube (no 5-6), which was passed through the cystic duct (after making a small nick in the cystic duct) into the CBD. After the insertion of the catheter, a clip was applied snugly to prevent any back leakage of the contrast medium. Digital C-arm fluoroscopy provided the real time imaging of the biliary tree. In cases where the cystic duct could not be cannulated, contrast was directly injected into the CBD through a lumbar puncture needle (24Fr) percutaneuosly Figure (1).

On cholangiogram, we looked for any filling defect, its size, site, number of bile duct stones, and free passage of contrast into the duodenum and for any anatomical variations of the biliary tree. We selected transcystic or transcholedochal approach to remove CBD stones depending on the factors shown in Table (2).

CBD stones were extracted with the help of Dormia basket /balloon catheter, irrigation/ suctioning or by simply manipulating bile duct using blunt forceps. After retrieving the stones, the cystic duct stump was closed with clips or suture ligature and the gall bladder 

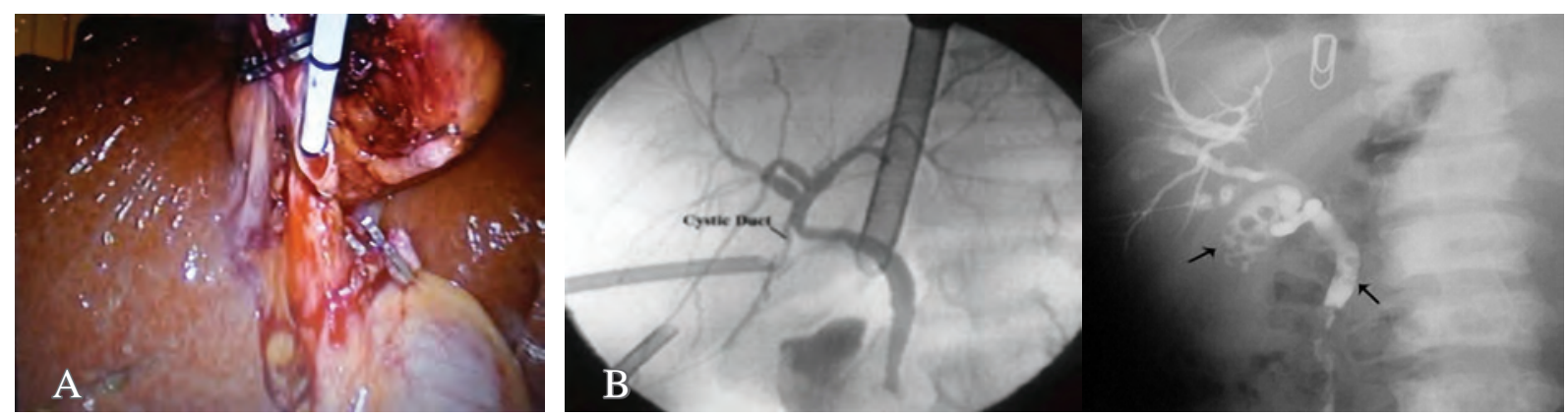

Figure (1): Intraoperative cholangiography (A) Transcystic catheter placement (B) C-arm image after contrast injection.
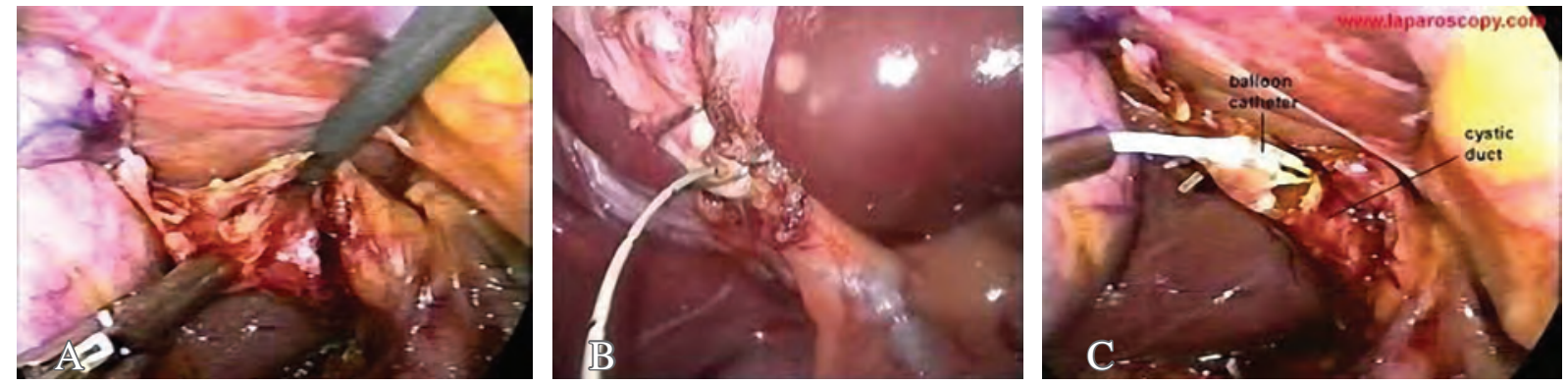

Figure (2): (A) Dissection of Calot trianglefig. (B) Insertion of ureteric catheter. (C) Transcystic exploration.
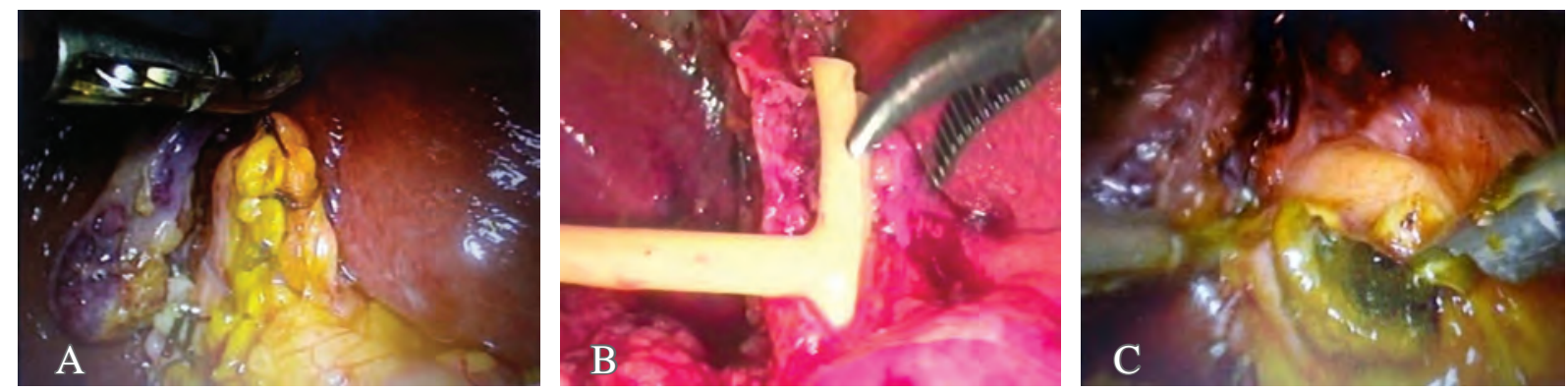

Figure (3): (A) Transcholedochal exploration with primary duct closure. (B) Closure over T-tube. (C) Choledochotomy incision with stone.

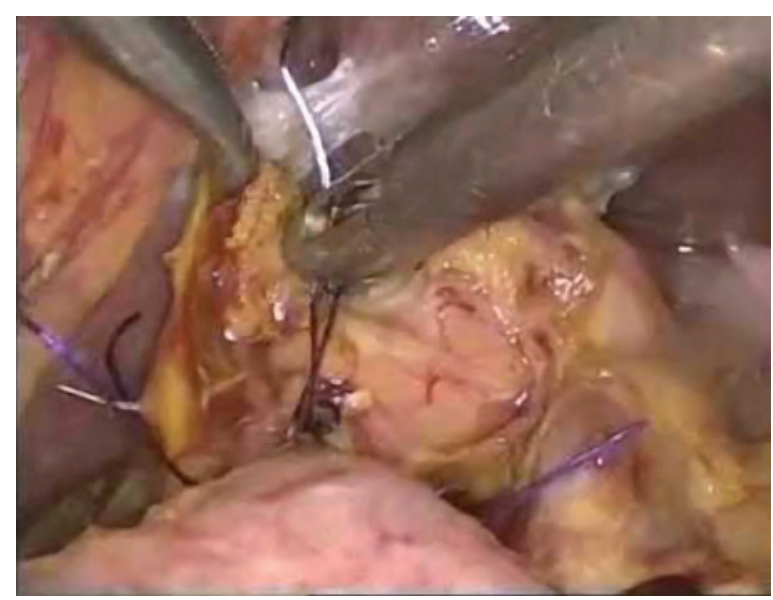

Figure (4): Choledochoduodenostomy.

was removed in the usual manner Figure (2).

Transcholedochal exploration was performed in the following manner. After opening up of the Calot's triangle, the anterior surface of the CBD was dissected carefully and choledochotomy was performed by 
Table (1): Predictors of CBD stone.

\begin{tabular}{|c|}
\hline 1) History / Clinical \\
\hline Jaundice within 6 months \\
\hline Pancreatitis within 6 months \\
\hline $\begin{array}{l}\text { 2) Biochemical } \\
\qquad \text { - Bilirubin }>10 \% \text { of the normal at the higher side }\end{array}$ \\
\hline $\begin{array}{l}\text { - One or more liver function enzymes (Alkaline phosphatase, aspartate } \\
\text { aminotransferase, alanine aminotransferase) }>10 \% \text { of the normal at the higher side }\end{array}$ \\
\hline - Amylase $>10 \%$ of the normal at the higher side \\
\hline $\begin{array}{l}\text { 3) Ultrasound } \\
\text { Dilated CBD }>7 \mathrm{~mm}\end{array}$ \\
\hline CBD stone \\
\hline
\end{tabular}

Table (2): Factors influencing approach. ${ }^{7}$

\begin{tabular}{|l|l|l|}
\hline Factor & Transcystic approach & Transcholedochal \\
\hline No. of stones & $<3$ CBD stones & $>3$ CBD stones \\
\hline Size of stone & Stone size $<5 \mathrm{~mm}$ & Stone size $>5 \mathrm{~mm}$ \\
\hline CBD dilatation & CBD dilatation $<1 \mathrm{~cm}$ & CBD dilatation $>1 \mathrm{~cm}$ \\
\hline Location of stone & Distal CBD stone & $\begin{array}{l}\text { Proximal bile duct stones } \\
\text { Failed transcystic approach }\end{array}$ \\
\hline
\end{tabular}

Table (3): Our experience.

\begin{tabular}{|l|l|}
\hline Laparoscopic cholecystectomy & 450 \\
\hline Intraoperative cholangiogram & $45(10 \%)$ \\
\hline Detected to have CBD stone & $34(75.6 \%)$ \\
\hline Transcystic approach & $10(33.6 \%)$ \\
\hline Transcholedochal approach & $20(66.4 \%)$ \\
\hline Choledochotomy closure over t tube & $3(10 \%)$ \\
\hline Primary CBD closure with endobiliary stent & $15(50 \%)$ \\
\hline Choledochoduodenostomy & $2(6.6 \%)$ \\
\hline Closure over an antegrade stent & 01 \\
\hline Closure over an endobiliary stent & 01 \\
\hline
\end{tabular}

Table (4): Our complications

\begin{tabular}{|l|l|}
\hline Conversion in 4 patients & $11.7 \%$ \\
\hline Minor bile leak in 2 patients & $5.8 \%$ \\
\hline Wound infection in 3 patients & $8.8 \%$ \\
\hline Ileus in 1 patient & $2.9 \%$ \\
\hline Pancreatitis in 2 patients & $5.8 \%$ \\
\hline
\end{tabular}

a longitudinal incision with the help of endoscopic knife just below the insertion of the cystic duct into the bile duct. In the initial few cases we used stay suture before performing choledochotomy but later we incised bile duct longitudinally without any 
stay sutures. The stones were retrieved by spontaneous evacuation while incising the bile duct, blunt instrumental pressure with atraumatic forceps, Dormia basket, Fogarty balloon catheter or irrigation and suction.

Completion cholangiography or choledochoscopy was performed to assess the completeness of the procedure.

Choledochotomy was closed over t-tube with continuous $3 / 0$ vicryl suture in $3(10 \%)$ of patients Figure (3). We did primary closure of CBD in the majority of cases 15 (50\%), after assessing the clearance of the CBD and in one case we placed a trancystic antegrade stent (using 5Fr ureteric catheter) which was brought out via cystic duct. The cystic duct was ligated twice with the antegrade stent in situ using $2 / 0$ vicryl. In another case we placed a modified endobiliary stent (commercially available endobiliary stent, Fr 7 and $9 \mathrm{~cm}$ in length, with elimination of the proximal flap on the biliary side) into the distal CBD with distal flange through the papilla into the duodenum with the aid of choledochoscope. While choledochoduodenstomy have been performed in 2 patients Figure (4).

After bile duct closure, cholecystectomy was performed in the usual manner. We placed an infrahepatic tube drain in all the cases which was usually removed on Day 3-4 post operativelyas the output decreased below $30 \mathrm{ml} /$ day.

\section{Results:}

45 patients were subjected to selective IOC due to the suspicion of CBD stones based on the predictors of CBD stones as given in Table (1). ${ }^{8}$

Out of the 45 patients, 35 patients were female and 10 were male. The mean age group of the patients was 42 years (25-68 years). Out of the 45 patients undergoing IOC, CBD stones were detected in 34 cases $(75.6 \%)$. Out of 34 cases, 15 cases had a preoperative diagnosis of CBD stones (US)and the rest were picked up on IOC. We removed CBD stones transcystically or by choledochotomy as shown in Table (3).

Median duration of the procedure was 75 min $(60-150 \mathrm{~min})$. At the beginning of our experiencethedurationwaslonger, particularly in patients undergoing choledochotomy after failed trans-cystic extraction. The time taken for choledochotomy was 30-40 min more than that for the transcystic approach.

Post-operative course was similar to that of LC in the patients where transcystic exploration was done and the patient was discharged on post-operative Day (POD) 3.

In patients who had undergone transcholedochal approach, t-tube was clamped on (POD) 4 and was removed on (POD) 7 without routine T-tube cholangiogram. Intra-abdominal drain was removed as the patients started oral diet and the drain output $<30 \mathrm{ml} /$ day. All the patients were discharged on (POD) 7, except the 2 patients who had minor biliary leak which settled on conservative management discharged in 2-3 days later on.

In patients where we put antegrade stent, we removed the stent on (POD) 4 and the patient was discharged on day 5 .

We placed modified endobiliary stent laparoscopically into the CBD across the duodenum in one patient and the stent was removed after 4 weeks by endoscopy.

We did not have any mortality and the various complications which we encountered during laparoscopic CBD exploration are shown in Table (4).

We had to convert the laparoscopic procedure to conventional open CBD exploration in 4 patients. Out of these, we could not clear the bile duct in 3 patients due to multiple stones and in 1 patient there were severe adhesions present in the Calot's triangle and the bile duct could not visualized properly. In 2 patients we had minor bile leak after removal of t-tube which settled on conservative treatment in 2-3 days. Minor wound infection in the form of erythema and serous collection at the port site occurred in 2 patients and 1patient had small hematoma at the epigastric port site through which gall bladder was extracted had treated conservatively. Mild pancreatitis developed in 2 patients which resolved on conservative treatment in 2-3 days.

Follow-up after 6 months were completed 
in 25 patients $(83.3 \%)$ and no missed/ residual stone was found. Rest of the patients were lost to follow-up.

\section{Discussion:}

The best treatment of choledocholithiasis must be simple, reliable, readily available, cost-effective and patient-friendly. The incidence of CBD stones in patients undergoing LC is $10-16 \%$, so the surgeon must be prepared to manage CBD stones appropriately, depending on whether the diagnosis is made preoperatively or during the surgery. ${ }^{10}$ If choledocholithiasis is suspected preoperatively, recommendations in past were to get an ERCP and if stones were found, ES and extraction of stones.

But there are a few important variables to consider before committing ourselves to this so-called old testimony. Firstly, ERCP is successful in $>90 \%$ of the patients but it is highly dependent on the availability of an experienced endoscopist to achieve such a high success rate. ${ }^{11}$ The second consideration is that of cost and the need for a second stage procedure. ${ }^{12,13}$ If a stent is placed then removal needs another endoscopy, usually after 4 weeks. The intervening period requires antibiotics in many cases which further increases the cost factor. Thirdly, there are no selective criteria that can accurately predict the presence of CBD stone. ${ }^{14}$ Taking into account all the positive predictors (history,clinical, biochemical, and sonography) for CBD stones, in most of the series reported in the literature, positive ERCP occurs in only up to $30-35 \%$ of the cases. ${ }^{15}$ On the other hand if we do routine IOC, we detect the stone in about $10 \%$ of cases and on selective IOC, CBD stones can be detected in about $25 \%$ of the cases. ${ }^{16}$

Finally, the risk of potential complications of ERCP should be considered. Although the complication rate is decreasing with increasing experience, pancreatitis continues to be a problem in most of the reported series, with an incidence of morbidity up to $7 \%$ and mortality of $0.2-2.3 \% .{ }^{17}$ The sphincter of Oddi (SOD) provides a barrier that prevents duodeno-biliary reflux and this function is permanently lost after sphincterotomy. ${ }^{18}$ ES increases duodenal reflux and a higher rate of bactibilia (60\%) with the increasing rate of recurrent biliary stone formation. ${ }^{19}$

This duodeno-biliary reflux further causes biliary epithelium to adapt to a new environment. Chronic bactibilia, in addition to pancreatic reflux (which is proved to be responsible for higher rates of malignancy in case of congenital choledochal cyst, may lead to neoplastic changes in the biliary epithelium. ${ }^{20,21}$

LCBDE has considerable advantages for treating both gall bladder and bile duct stones in a single stage without any preoperative examination to detect the presence of stones in CBD. ${ }^{22,23}$ The main drawback of LCBDE is the increased operative time and the cost involved, particularly with the use of choledochoscope.

There is a possibility of false positive cholangiograms in open procedure but did not encounter this problem. LCBDE is successful in $75-95 \%$ of the patients and is comparable to the endoscopic treatment. Moreover,if the endoscopic treatment fails, particularly inthe postoperative setting, this may require a third stage open procedure. While if LCBDE fails, one can convert at the same time. Also as the experience is increasing in LCBDE, the success rate will further improve. (Liebermann et al), and (Martin et al); found that the single stage procedure had significant lower morbidity and shorter hospital stay resulting in lower cost than those of staged ERCP and LC. 24,25

In our study, patients who were unfit for operation orthose with severe pancreatitis/ cholangitis or with previous upper abdominal surgery or with CBD stone but bile duct dilatation $<6 \mathrm{~mm}$ subjected to ERCP and were excluded from the current study. We have deliberately not done ERCP in the study group patients considering the cost, twostage procedure, risk of complications and the possibility of failure.

Certainly, ERCP has been an important modality for treating leftover CBD stone after LC. The current trend is to utilize ERCP less, preoperatively, while expanding its role 
in the postoperative setting. ${ }^{26}$

Various randomized controlled studies comparing the two-stage (ERCP with LC) procedure and one-stage LC with LCBDE, showed that the one-stage procedure resulted in a shorter stay and similar stone clearance rates. ${ }^{26,27}$

Transcystic CBD exploration is preferred as it is easy, more physiological, associated with less complications, does not require t-tube placement and intra-corporeal suturing and the post-operative course is almost similar to patients undergoing LC alone. However, a transcholedochal approach is a must if there are-multiple stone $(>5)$, stone $>6 \mathrm{~mm}$, proximal stone, CBDsize $<6$ $\mathrm{mm}$, cystic duct size $<4 \mathrm{~mm}$ (too narrow to pass choledochoscope), and if there is any anatomical variation of the biliary tree. ${ }^{28}$

Traditionally, CBD exploration is accompanied by t-tube drainage of CBD. Nevertheless, there are a few disadvantages, inconvenience, and discomfort, delayed recovery, longer stay, risk of tube displacement, risk of infection and rarely, fracture of tube fragment, and retention in the CBD. ${ }^{28}$

Lange et al; first reported laparoscopic CBD primary closure with antegrade stent. ${ }^{29}$ Recently, many studies have shown feasibility and potential advantages of antegrade stent which include decompression of CBD postoperatively, facilitation of ERCP cannulation postoperatively and early return to full activity. ${ }^{30}$

Nowadays the combined laparoendoscopic approach to CBD stone is talked about in which a modified plastic biliary stent is used (modified by breaking the proximal flange). ${ }^{8}$ Potential problems with the plastic stent are bile leak, stent occlusion, early stent migration and the need of future endoscopy for the removal of the stent. 31,32

Out of 45 patients we found CBD stones in 34 patients. We were able to successfully remove stones in 30 patients and in 4 patients, we had to convert to open CBD exploration as we were not able to remove completely all the stones laparoscopically.

Now we have every confidence in the technique of LCBDE, our success rate is
$88.2 \%$ (4 conversions out of 34 explorations), there was no major complication, and in follow-up, no residual stone was found. Our operating time is also decreasing as all the team members are getting familiarized with the technique and equipments. Although we still rely on ERCP and ES for high risk patients or those who are unfit for operation or those with severe pancreatitis/ cholangitis or those who are diagnosed as to have CBD stone with bile duct diameter $<6 \mathrm{~mm}$.

Our results are good and improving; we need time and more efforts to be comparable to the published data in the literature, in terms of stone clearance, minimal complications, a shorter hospital stay, and rapid recovery time. 33,34 The optimal management of choledocholithiasis remains unclear in the present laparoscopic era. Management at a single stage is the optimal approach in terms of safety, patient satisfaction and cost-effectiveness.

\section{Conclusion:}

CBD stones are associated with about $10-16 \%$ of the patients undergoing cholecystectomy. Treatment algorithms have changed for CBD stones with the advent of endoscopic management which is now getting further modified with the advancement in laparoscopic surgery.

The treatment of CBD stones depends on the resources available, technical limitations, and the surgeon's expertise. Laparoscopic CBD exploration is a safe, feasible and single-stage option for the management of CBD stones. In spite of its difficulty and learning curve is slow and demanding, it is improving in our department 8B unit, more data and time are needed to improve our technique and outcome.

\section{Reference:}

1- Curet MJ, Pitcher DE, Martin DT, Zucker KA: Laparoscopic antegrade sphincterotomy: A new technique for the management of complex choledocholithiasis. Ann Surg 1995; 221: 149-155.

2- Southern Surgeon's Club: A prospective analysis of 1518 Laparoscopic cholecystectomies. N Engl J Med 1997; 
324:1073-1078.

3- Petelin JB: Laparoscopic common bile duct exploration. In: Surgical Laparoscopy; Zucker KA. $2^{\text {nd }}$ Ed. Lippincott: Williams and Wilkins 2001; 23: 809-816.

4- Giordano L, Phillips EH: Laparoscopic common bile duct exploration. In: Soper NJ, Swanstorm LL, Eubanks WS. Mastery of Endoscopic and Laparoscopic Surgery. $2^{\text {nd }}$ Ed. Lippincott: Williams and Wilkins 2005; 319-332.

5- Tokumara H, Umezawa A, Cao H, Sakamoto N, Imoaka Y,Oucchi A, et al: Laparoscopic management of CBD stones: Transcystic approach and choledochotomy. J Hepatobiliary Pancreatic Surg 2002; 9: 206-212.

6- Perissat J, Collet DR, Belliard R: Gallstone: Laparoscopic treatment, intraoperative lithotripsy followed by cholecystostomy or cholecystectomy. Endoscopy 1989; 21: 373-374.

7- Thomson MH, Tranter SE: All comers policy for laparoscopic exploration of the bile duct. BJS 2002; 89: 1608-1612.

8- Soltan HM, Kew L, Toouli J: A simple Scoring system for predicting bile duct stones in patients with choledocholithiasis. $J$ Gastrointest Surg 2001; 5: 434-437.

9- Wagner AJ, Traverso WL: Laparoscopic common bile duct exploration. In: Cameron JCurrent Surgical Therapy, $8^{\text {th }}$ Ed. Baltimore: Elsevier Mosby; 2004. 1199-1203.

10- Kim EK, Lee SK: Laparoscopic treatment of choledocholithiasis using modified biliary stents. Surg Endo 2004; 18: 303-306.

11- Freeman ML, Nelson DB, Sherman S, Haber GB, Herman ME, Dorsher PJ, et al: Complication of endoscopic biliary sphincterotomy. $N$ Engl J Med 1996; 335: 909-918.

12- Bergman JJGHM, Rouws EAJ, Fockenc P, Van Berkel AM, Bossuyt PM, Tijssen JG, et al: Randomized trial of endoscopic balloon dilation Vs endoscopic sphincterotomy for removal of CBD stone. Lancet 1997; 49: 1124-1149.

13- Urbach DR, Khajanchee YS, Jobe BA, Standage BA, Hansen PD, Swanstorm LL: Cost effective management of CBD stones; decision analysis of the use of ERCP, intraopearative cholangiogram and laparoscopic CBD exploration. Surg Endo 2001; 15: 4-13.

14- Decker G, Borie F, Millat B, Berthou JC, Deleuze A, Drouard F, et al: One hundred laparoscopic choledochotomies with primary closure of the CBD. Surg Endo 2003; 17: 12-18.

15- Petelin JB: Laparoscopic common bile duct exploration. Surg Endo 2003 ; 17: 1705-1715.

16- Berci G, Morgensem L: Laparoscopic management of CBD stones: A multiinstitutional SAGES study. Surg Endo 1994; 8: 1168-1175.

17- Tranter Se, Thompson MH: Comparison of endoscopic sphincterotomy and laparoscopic exploration of CBD. BJS 2002; 89: 1495-1504.

18- Bergman HM, Van Berkel AM, Groen AK, Schoeman MN, Offerhaus J, Tytgat GN, et al: Biliary manometry, bacterial characterstics, bile composition and histologic changes fifteen to seventeen yr after ES. Gastrointest Endosc 1997; 45: 400-405.

19- Sand J, Airo I, Hiltranen KM, et al: Changes in biliary bacteria after endoscopic cholangiography and sphincterotomy. Am Surg 1992; 58: 324-328.

20- Tanaka M, Takahta S, Konomi H, Matsunage $\mathrm{H}$, Yokohata K,Takeda T, et al: Long term consequences of endosphincterotomy for the bile duct stones. Gastointest Endosc 1998; 48: 465-469.

21- Ekbom A, Hsieh C, Yuen J, Trichopoulos D, Mclaughlin JK, Lan SJ, et al: Risk of extrahepatic bile duct cancer after cholecystectomy. Lancet 1993; 342: 1262-1265.

22- Cushiery A, Lezoche E, Morino E, Crace E, Lacy A, Toouli J, et al: EAES multicentre prospective randomized trail comparing two stage Vs single stage management of patients with gall stones and choledocholithiasis. Surg Endo 1999; 13: 952-959.

23- Rhodes M, Sussman L, Cohen L, Lewis MP: Randomized trial of laparoscopic exploration of CBD Vs postoperative ERCP for CBD stones. Lancet 1998; 351: 159-161.

24- Leibermann MA, Philips EH, Carroll BJ, Fallas MJ, Rosenthal R, Hiatt J: Cost effective management of complicated choledocholithiasis: Laparoscopic transcystic exploration vs ES. J Am Coll Surg 1996; 182: 488-494.

25- Martin IJ, Baieley IS, Rhodes M, O'Rourke N, Nathanson L, Fielding G: Towards T-tube free laparoscopic bile duct exploration. Am Surg 1998; 228: 29-34.

26- Sue B, Escat J, Cherqui D, Fourtainer G, Hay JM, Fingerhut A, et al: Surgery Vs endoscopy as primary treatment in symptomatic patients 
with suspected CBD stones; A multicentre randomized trial. French Association for surgical research. Arch Surg 1998; 133: 702-708.

27- Tai CK, Tang CN, Ha JPY, Chau CH, Siu WT, Li MKW: Laparoscopic exploration of CBD in difficult choledocholithiasis. Surg Endo 2004; 18: 910-914.

28- Wu JS, Soper NJ: Comparison of laparoscopic choledochotomy closure techniques. Surg Endo 2002; 16: 1309-1313.

29- Lange V, Rau HG, Schardey HM, Meyer G: Laparoscopic stenting for protection of CBD sutures. Surg Laparosc Endosc 1993; 3: 466-469.

30- Dorman JP, Franklin ME, Glass JL: Laparoscopic CBD exploration through choledochotomy. Surg Endo 1998; 12: 926-928.

31- Isla AM, Griniatsos J, Karvounis F, Arbuckle JD: Advantages of Laparoscopic stented choledochorrhaphy over T-tube placement. BJS 2004; 91: 862-866.

32- Fanelli RD, Gersin KS, Mainella MT: Laparoscopic endobiliary stenting significantly improves success of postoperative ERCP in low volume centers. Surg Endo 2002; 16: 487-491.

33- Petelin JB: Laparoscopic approach to CBD pathology. Surg Laparosc Endosc 1991; 1: 33-41.

34- Hunter JG, Soper NJ: Laparoscopic management of bile duct stones. Surg Clin North Am 1992; 72: 1077-1097. 